\title{
VPPA welds of Al-2024 alloys: analysis and modelling of local microstructure and strength
}

\author{
S.C. Wang, F. Lefebvre, J.L. Yan, I. Sinclair and M.J. Starink \\ Materials Research Group, School of Engineering Sciences, \\ University of Southampton, Southampton. SO17 1BJ, UK
}

\begin{abstract}
The microstructural features of variable polarity plasma arc welded Al-Cu-Mg 2024-T351 with 2319 filler have been studied by TEM, SEM and DSC. Fusion zone, partial melting zone, resolutionising zone, overageing (for $\mathrm{S}$ phase), peak ageing (for $\mathrm{S}$ phase) and under ageing zones (for $\mathrm{S}$ phase) have been identified. The $\Omega$ phase has been observed between re-solutionising zone and peak ageing zone. The hardness profile contains two peaks. The microstructure development, and resulting hardness and yield strength profiles are modelled using a model which combines primary precipitation, resolution, partial/full melting and resolidification (Scheil type) and reprecipitation, in a two precipitate - two mechanism approach. Hardness profiles and microstructures are accurately predicted. The hardness peak in the re-solutionising zone is due to re-solutionising and subsequent $\mathrm{Cu}-\mathrm{Mg}$ co-cluster formation; and the second hardness peak is caused by $\mathrm{S}$ phase strengthening.
\end{abstract}

Keywords: Al-Cu-Mg alloy, microstructure modelling, TEM, DSC, co-clusters, hardness, VPPA weld, solidification 


\section{Introduction}

\subsection{Welding of Al based alloys; strategy and aims of the work}

The traditional method of joining components in many structural applications is through the use of mechanical fasteners (rivets), which makes assembling primary structures extremely time consuming. By replacing riveted joints with fusion welds, considerable savings in the manufacturing process can be achieved, as well as weight reduction and improvement in mechanical performance [1,2]. In recent years significant attention has been focused on manufacturing costs in aerospace engineering. New techniques in aircraft component manufacture are being developed to provide simultaneous weight saving and cost saving. In this context, the variable polarity plasma arc (VPPA) welding was considered industrially in the last ten years to produce high quality welds. One potential application in aeronautical industry is that the welding of aluminium alloys may be used in stringer-skin panels.

In a welding treatment the temperature in the fusion zone and adjacent zones will rise to a significant extent such that reactions will cause changes in the microstructure $[3,4]$. These microstructural changes will in turn cause the mechanical properties in these zones to change. If the material was originally in a condition that was optimised to achieve the best mix of mechanical properties for the given alloy, then it can be expected that in the zones affected by the welding the balance of properties is less favourable [5]. In order to be able to understand and optimise welding, and pre- and post-welding thermal treatments for the welds, a detailed understanding of the microstructural changes occurring in the alloy is needed. And in order to quantitatively predict properties of the welds we need to develop models that contain predictions of temperature in the weld and heat affected zones, microstructural changes due to the latter and the mechanical properties caused by the microstructure [6]; and verify these models by correlating them to observed microstructures.

In this paper, the microstructure of the Al-Cu-Mg 2024-T351 alloys, welded by VPPA welding is studied. 2024-T351 alloys are typically used for damage tolerant applications in aircraft, especially the lower wing structure [7]. The hardness variations in the heat-affected zones (HAZs) of the welds will be investigated in detail and correlated to the microstructures which are studied by means of TEM and SEM (transmission and scanning electron microscopy) and differential scanning calorimetry (DSC). A further key part of the work is an attempt to predict the local strength of the weld based on the temperature history and nano/microstructure 
development of the material. This work part of the work is based on new insights into the relation between nano sized co-clusters that was recently developed [8,9]. The obtained hardness and microstructural data will be compared to a model that predicts the microstructural changes and resulting strength of $\mathrm{Al}-\mathrm{Cu}-\mathrm{Mg}$ alloys during ageing.

\subsection{Precipitation in Al-Cu-Mg based alloys}

The strengthening in 2024 alloys is attributed to the precipitation sequence that ultimately leads to $\mathrm{S}$ formation. In the early 50s, Bagaryatsky [10] first proposed a 4-stage precipitation sequence for the ageing of $\mathrm{Al}-\mathrm{Cu}-\mathrm{Mg}$ alloys:

$$
\mathrm{SSS} \rightarrow \mathrm{GPB} \text { zone } \rightarrow \mathrm{S}^{\prime \prime}(\mathrm{GPB} 2) \rightarrow \mathrm{S}^{\prime} \rightarrow \mathrm{S}\left(\mathrm{CuMgAl}_{2}\right)
$$

where SSS stands for supersaturated solid solution and GPB was termed as Guinier-PrestonBagaryatsky by Silcock [11]. Orthorhombic [10,12], cubic [11], tetragonal [13,14] and monoclinic [15] structures have been proposed for the S"/GPB2 structure, but none of these has been independently confirmed. Indeed, other researchers (e.g., Wilson and Partridge [16] and Ringer and co-workers $[17,18]$ ) were unable to confirm the presence of the $S^{\prime \prime}$ phase. Recently, two new structures for GPB2/S" were proposed, both are orthorhombic and can be considered as an ordering of $\mathrm{Cu}$ and $\mathrm{Mg}$ atoms within the face centred cubic Al structure. One is space group Imm2 with lattice parameters $\mathrm{a}=0.4 \mathrm{~nm}, \mathrm{~b}=1.6 \mathrm{~nm}$ and $\mathrm{c}=0.4 \mathrm{~nm}$ and composition of $\mathrm{Al}_{5}(\mathrm{Cu}, \mathrm{Mg})_{3}[19,20]$; the other is orthorhombic with lattice parameters $\mathrm{a}=0.4 \mathrm{~nm}, \mathrm{~b}=1.2 \mathrm{~nm}, \mathrm{c}$ $=0.4 \mathrm{~nm}$ and space group Cmmm [21].

It is widely accepted now that $\mathrm{S}^{\prime}$ is continuous rather than distinct to $\mathrm{S}$ phase (e.g. [22,23]). For the present paper, we will not use the term $S^{\prime}$ phase, and instead use the indication semi-coherent or rod-shaped $\mathrm{S}$ phase or simply $\mathrm{S}$ phase precipitates. The most accepted structure for $\mathrm{S}$ phase appears to be the one proposed by Perlitz and Westgren [24], which has a Cmcm structure with lattice parameters $\mathrm{a}=0.400 \mathrm{~nm}, \mathrm{~b}=0.923 \mathrm{~nm}, \mathrm{c}=0.714 \mathrm{~nm}$ and forms as laths on $\{210\} \mathrm{Al}$ habit planes and is elongated along the $<100>\mathrm{Al}$ directions. The orientation relationship between $\mathrm{S}$ and aluminium matrix is [10]:

$$
[100]_{\mathrm{Al}} / /[100]_{\mathrm{S}},[02 \overline{1}]_{\mathrm{Al}} / /[010]_{\mathrm{S}},[012]_{\mathrm{Al}} / /[001]_{\mathrm{S}}
$$

There are in total 12 orientation relationships which are crystallographically equivalent to the above one. The maximum hardness in stretched and aged 2024 type alloys corresponds to the 
stage where $\mathrm{S}$ phase formation is nearly completed and the diameter of the $\mathrm{S}$ phase rods is about $5 \mathrm{~nm}[25]$.

Recent work $[8,18]$ using three-dimensional atom-probe indicates that $\mathrm{Cu}-\mathrm{Mg}$ co-clusters are responsible for rapid hardening in $\mathrm{Al}-\mathrm{Cu}-\mathrm{Mg}$ alloys. This stage accounts for approximately $60 \%$ of the total hardness increase during ageing [26]. During this rapid hardening no distinct precipitate can be detected by conventional TEM but DSC experiments clearly show a dissolution effect evidencing that a metastable pre-precipitate has formed [27]. Evidence for the existence of the GPB zones, with a structure distinct from the random structure in co-clusters, is limited [23].

In summary, the most recent work indicates that the precipitation sequence in $\mathrm{S}$ phase forming $\mathrm{Al}-\mathrm{Cu}-\mathrm{Mg}$ based alloys is best represented as [28]:

$$
\mathrm{SSS} \rightarrow \mathrm{Cu}-\mathrm{Mg} \text { co-clusters } \rightarrow \mathrm{S}^{\prime \prime} / \mathrm{GPB} 2 \rightarrow \mathrm{S}\left(\mathrm{CuMgAl}_{2}\right)
$$

In addition to the main sequence related the $\mathrm{S}$ phase, also $\Omega$ phase has been reported to occur in 2024 type alloys. The $\Omega$ phase has been previously proposed as monoclinic [29,30], hexagonal [31], orthorhombic [32] and tetragonal [33]. Nevertheless, viewed from [001] $]_{\mathrm{Al}}$, all of these proposed $\Omega$ structures give the same reflections on $1 / 3\{220\}_{\mathrm{Al}}$ and $2 / 3\{220\} \mathrm{Al}$ [23]. The orthorhombic structure, with lattice parameters of $a=0.496 \mathrm{~nm}, b=0.859 \mathrm{~nm}, c=0.848 \mathrm{~nm}$, is accepted in most recent publications. The orientation relationship between the matrix and $\Omega$ precipitates is

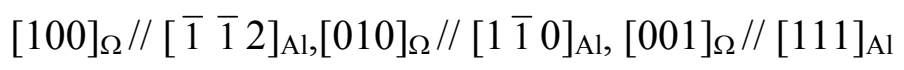

The above orientation relationships between $\Omega$ and matrix are consistent with one of 22 independent orientation relationships between $\theta$ and matrix (the orientation called 'Vaughan II' in [34]). The $\theta$ phase has tetragonal structure (space group I4/mcm) with $a=0.6067 \mathrm{~nm}$ and $c=$ $0.4874 \mathrm{~nm}$. The $\Omega$ phase has been considered as a slightly distorted form of $\theta$ phase [33]. Indeed, the atomic coordinates in both phases are extremely close (the difference is less than 0.86 $\%$ ) [23]. To achieve perfect atomic matching of $\theta$ phase on the $\{111\}$ Al planes, a small distortion with the $c$ lattice parameter increasing $1.76 \%$ (to $0.496 \mathrm{~nm}$, i.e., $c$ lattice parameter of $\Omega$ phase) is needed. 


\section{Experimental procedures}

The 2024-T351 alloy was supplied in the form of $13 \mathrm{~mm}$ plate. Filler wire of 2319 alloy was used to ensure a smooth profile without undercut. The welding was performed at a travel speed of $17 \mathrm{~cm} / \mathrm{min}$ in vertical up position. Welds were parallel to the L-direction (long-transverse direction) of the parent materials (2024 alloys). Further welding details were presented elsewhere ${ }^{3}$. The nominal chemical compositions of the two alloys are given in the Table 1 .

Table 1 Chemical composition of 2024 and $2319(\mathrm{Wt} \%)$

\begin{tabular}{ccccccc}
\hline Alloy & $\mathrm{Cu}$ & $\mathrm{Mg}$ & $\mathrm{Mn}$ & $\mathrm{Si}$ & $\mathrm{Fe}$ & $\mathrm{Al}$ \\
\hline 2024 & 4.2 & 1.5 & 0.6 & $<0.5$ & $<0.5$ & $\mathrm{Bal}$ \\
2319 & 6.2 & - & 0.3 & $<0.2$ & $<0.3$ & $\mathrm{Bal}$ \\
\hline
\end{tabular}

For the micro-hardness measurements and SEM observation, the weld plate was skimmed (i.e. the surface to a depth $2 \mathrm{~mm}$ was removed) and then mechanical polished. Vickers microhardness tests were conducted using applied load and time of $1 \mathrm{~kg}$ and $15 \mathrm{~s}$ respectively. SEM was performed using a JEOL JSM $6500 \mathrm{~F}$ at $15 \mathrm{kV}$. Electron backscatter diffraction (EBSD) was performed using an HKL Channel 5 system attached to the FEG-SEM.

Slices of $0.4 \mathrm{~mm}$ thickness were obtained at a range of locations across the weld for differential scanning calorimeter (DSC) tests and TEM observations. DSC measurements were performed on Perkin Elmer Pyris 1 at a constant rate $10^{\circ} \mathrm{C} / \mathrm{min}$. The reference sample was an empty pure aluminium sample pan, tests were carried out using a nitrogen gas flow and heating rate of $10^{\circ} \mathrm{C} / \mathrm{min}$. Baseline correction procedures are outlined elsewhere [25], all presented DSC curves reflect the heat flow due to reactions. Due to the strong differences in the DSC curves from the different samples, slight inaccuracies in baseline determination in the order of $\pm 510^{-3} \mathrm{~W} / \mathrm{g}$ may remain [35].

Disks of $3 \mathrm{~mm}$ in diameter (for TEM) were punched out from these slices, ground to around $0.25 \mathrm{~mm}$ in thickness and then electropolished using a solution of $\mathrm{HNO}_{3}$ and methanol $(1: 3$ in volume). TEM foils were examined using a JEOL 2000FX microscope operating at 200kV. 


\section{Experimental Results}

\subsection{Vickers Hardness Measurements}

Fig. 1 shows half of a hardness trace across the VPPA weld from the surface of skimmed 2024 alloy specimens. It is clear that the hardness presents a minimum at the centre (i.e. in the fusion zone, $0-6 \mathrm{~mm})$. Two hardness peaks in the HAZ $(6-30 \mathrm{~mm})$ are noticed. TEM observations were carried out to show the microstructure of the material at the key points. Six different locations from the weld centre to the parent plate were studied.

\subsection{Electron Microscopy Study}

As the variations of hardness correspond to the microstructural changes, especially the changes in the precipitates, detailed TEM and SEM studies have been carried out.

Fig. 2 shows the orientation maps obtained from EBSD from the fusion centre to HAZ and the phase distributions on positions 1 and 2. Different regions may be identified: (a) the central region of the fusion zone with an equiaxed dendritic structure; (b) the end of the fusion zone exhibiting a columnar dendritic structure; (c) a transition zone between the fusion zone and the HAZ, which is a partial melting zone. In the fusion zone centre (Position 1), EDS analysis and selected area diffraction (SAD) in the TEM (Fig. 3) revealed that two kinds of coarse particles dominate the structure: one constitutes of the eutectic phases $\theta\left(\mathrm{Al}_{2} \mathrm{Cu}\right)+\mathrm{S}\left(\mathrm{Al}_{2} \mathrm{CuMg}\right)$, and another is a Al-Cu-Fe-Mn-Si phase. The $(\theta+\mathrm{S})$ eutectics distribute as dendrites or in grain boundaries, whereas the phases containing $\mathrm{Cu}, \mathrm{Fe} \mathrm{Mn}$ and $\mathrm{Si}$ are mostly observed on the grain boundaries in which SAD shows that this phase exhibits ten-fold symmetry confirming its quasicrystalline nature (Fig. 3). In contrast, in the transition zone (partial melt zone, position 2), instead of quasicrystalline phase, two crystal phases $\mathrm{Al}_{7} \mathrm{Cu}_{2}(\mathrm{Fe}, \mathrm{Mn})$, which has a tetragonal structure of $\mathrm{P} 4 / \mathrm{mnc}$ and lattice parameters of $a=0.6336 \mathrm{~nm}, c=1.487 \mathrm{~nm})$, and $\mathrm{Al}_{12}(\mathrm{Fe}, \mathrm{Mn})_{3} \mathrm{Si}$, which is a body centred cubic structure of $\operatorname{Im} 3 \mathrm{~m}$ and lattice parameter of $a=1.25 \mathrm{~nm}$, were confirmed both by EDS and SAD in TEM. Such observations are consistent with other work on coarse phases in 2024 alloys [36]. It is likely that the quasicrystalline phase is related to the fast cooling speed in the melting zone.

From edge of the fusion zone (melting zone) to about $5 \mathrm{~mm}$ from the weld centre, numerous approximately spherical particles were observed besides a few dendrites as shown by the SEM backscatter electron image in Fig. 4. The average size of these compounds decreases until they disappear at position 2. These particles show eutectic morphologies (see the enlargement in the 
insert of Fig.4), and EDS shows the white phase to be $\mathrm{Cu}$ rich and the grey phase to be $\mathrm{Cu}$ and $\mathrm{Mg}$ rich, thus identifying them as $(\theta+\mathrm{S})$ eutectic phases. No precipitates were detected by TEM. (But DSC shows co-clusters/zones are present, see below.) No dispersoid phases ( $\left.\mathrm{T}-\mathrm{Al}_{20} \mathrm{Cu}_{2} \mathrm{Mn}_{3}\right)$ were detected either.

Fig. 1 shows that the heat affected zone extends up to $40 \mathrm{~mm}$ from the weld centre. In these zones, the coarse phases are all crystalline and consistent to those in 2024 T351 alloys. However, the precipitates have been varied in type and size. Identification work for precipitates was carried out mainly on TEM.

In position 2 large precipitates (up to $1 \mu \mathrm{m}$ ) have been observed within the grains by TEM (Fig. 5). EDS shows their composition as close to $\mathrm{Al}_{2} \mathrm{Cu}$. The $\mathrm{SAD}$ pattern in $[001]_{\mathrm{Al}}$ shows weak extra diffraction spots on positions of $1 / 3$ and $2 / 3\{220\}_{\mathrm{Al}}$ which are consistent to reflections produced by $\Omega$ precipitates or $\theta$ phase (Vaughan II orientation). Further SAD shown in Fig. 6, revealed some weak reflections that are clearly split (one is indicated by the arrow). This is likely to be due to the presence of $\theta$ phase because the c lattice parameter of $\theta$ phase differs slightly from the aluminium matrix. Few $(\theta+\mathrm{S})$ eutectics were observed in the grains and $\mathrm{S}$ phase was observed in the grain boundaries (see the inserted figure). No S precipitates were observed in the grains.

TEM examination of position 3, where the first hardness peak is located, revealed much less and smaller (up to $200 \mathrm{~nm}$ ) $\Omega$ precipitates as compared to position 2 (Fig. 7). Most of them seem to form around the dispersoid $\mathrm{T}$ phase $\left(\mathrm{Al}_{20} \mathrm{Cu}_{2} \mathrm{Mn}_{3}\right)$ (Fig. $7 \mathrm{~b}$ ), which is consistent with previous observations on 2024 alloys aged at temperatures in excess of $200^{\circ} \mathrm{C}$ [37]. With the amount of dispersoid and Fe-containing intermetallic phases typically around $1 \mathrm{vol} \%$, it can be estimated that the amount of $\Omega$ precipitates is well below $1 \mathrm{vol} \%$. The well-defined $\Omega$ phase spots in the diffraction pattern (Fig. 7c), indicates the orientation relationship is identical to that in Fig. 5. In the SAD (Fig. 7c), some weaker, diffuse reflections can be seen. They are consistent with the GPB2/S" phase as was detected in recent work using high resolution electron microscopy (HREM) and electron diffraction $[19,20]$. This phase cannot be resolved in the conventional TEM.

Fig. 8a shows a TEM dark field image taken at position 4 corresponding to the minimum hardness in Fig. 1. The [001 $]_{\mathrm{Al}}$ SAD pattern shows the existence of two kinds of precipitates: $\mathrm{S}$ and $\Omega$ as shown in Fig. 8b,c. The thickness of $S$ precipitates may be up to $60 \mathrm{~nm}$, but also much 
finer S rods with diameters of about $20 \mathrm{~nm}$ are observed. The coarser S precipitates were even observed by high resolution SEM (Fig. 8d).

Fig. 9a shows a TEM bright field image at position 5 which corresponds to the second hardness peak (Fig. 1). The $[001]_{\mathrm{Al}} \mathrm{SAD}$ pattern shows the existence of two kinds of precipitates: $\mathrm{S}$ and $\Omega$ as shown in Fig. 9b,c. The $\mathrm{S}$ precipitates are much thinner than position 4 (note: the large rod phases are $\mathrm{T}-\mathrm{Al}_{20} \mathrm{Cu}_{2} \mathrm{Mn}_{3}$ ). Fig. $9 \mathrm{~b}$ shows the reflections from $\mathrm{S}$ phase are much stronger than those from $\Omega$ phase, which means the $\mathrm{S}$ precipitates (just over peaking ageing) dominate the microstructure.

Far away from the fusion centre, position 6 is nearly unaffected by heating, and the microstructure shows no difference to standard 2024-T351. Many T- $\mathrm{Al}_{20} \mathrm{Cu}_{2} \mathrm{Mn}_{3}$ dispersoids can be observed in TEM, as shown in Fig. 10. The SAD pattern shows no evidence of existence of any precipitates, and therefore, $\mathrm{Cu}-\mathrm{Mg}$ co-clusters are anticipated to be present at this position.

\subsection{DSC analysis}

Fig. 11 shows DSC curves for samples extracted from the 6 positions. The sections from 150 to $400^{\circ} \mathrm{C}$ depicted here reveal 4 main effects. $3 \mathrm{D}$ atom probe work has evidenced that in the present alloys room temperature hardening and hardening at $150^{\circ} \mathrm{C}$ is due to the formation of $\mathrm{Cu}-\mathrm{Mg}$ coclusters $[8,38,39]$, which become unstable at higher temperatures. Thus the endothermic effect up to about 230 to $250^{\circ} \mathrm{C}$ is attributed mainly to the dissolution of these clusters $[8,25,38]$. For position 3, the dissolution of GPB2/S" phase will also contribute to the endothermic effect. (GPB2/S" phase was detected by TEM, see section 3.2.) The presence of this dissolution effect for all samples, shows that all samples contain co-clusters. Subsequently, two exothermic effects are observed. The first one has been shown before to be due to $\mathrm{S}$ phase formation $[25,35]$. This effect peaks at about $260{ }^{\circ} \mathrm{C}$ for the two samples taken furthest away from the weld (positions 5 $\& 6)$. The only other precipitates observed in the extensive TEM work are the closely related $\Omega$ phase and $\theta$ phase, which is especially observed for samples taken closer to the weld. These $\Omega / \theta$ phases contribute to the second exothermic effect, but, as they are already present before the DSC runs, it is unlikely that any further formation can fully account for this second exothermic effect. Alternatively, the occurrence of S phase in two orientation relationship variants (which have been evidenced by TEM, see e.g. [40]) may influence the appearance of the double exothermic effect After completion of the exothermic precipitation effects, further heating leads to dissolution of the precipitates, which is reflected by the endothermic effect at the higher temperature end in all the DSC curves in Fig 11. 


\section{Model formulation, application and evaluation.}

To evaluate the hardness profile and the microstructure-property relations in a quantitative manner we have developed a model for yield strength and the hardness of welds based on the microstructure development, which includes both the fusion zone and the HAZ. The main aim of this section is to show that with suitable approximations and simplifications a model can be constructed that is accurate, transparent and takes account of the main hardening and softening reactions. The complete model draws together various new and existing models, which form sub-models within the new modelling elements.

The modelling strategy chosen here is different from works based on Kampmann-Wagner type models of precipitate evolution during the weld thermal cycle $[41,42]$. The reason for the present choice of modelling approach is that in the present alloy co-clusters are the main strengthening (pre-)precipitates and treatments of the precipitation of these co-clusters and the interaction with the formation of other precipitates within the Kampmann-Wagner framework are not available. Also, the present approach leads to a model formulation with analytical equations, thus avoiding the need for extensive computer time necessary within the Kampmann-Wagner framework. The latter is especially important if combined 3 dimensional heat diffusion-precipitationstrengthening models of welds are needed in which the 3D heat diffusion component, by necessity, will be computationally intensive.

\subsection{Heat treatment - microstructure - strength model}

A key part of the overall model for the weld strength and hardness is a recently derived model for the ageing and age hardening of Al-Cu-Mg alloys. The model considers the reactions in the solid state to be related to 3 phases, the Al rich phase, the co-clusters (or GPB zones) and the S phase,

and the model contains descriptions of the solvus of the $\mathrm{Cu}-\mathrm{Mg}$ co-clusters and $\mathrm{S}$ phase, the kinetics of the formation and coarsening of these (pre-)precipitates and the strengthening that these two (pre-)precipitates provide. The main equations governing the (semi-)equilibrium solvi and the kinetics of reactions in the solid state are described in the appendix. The strengthening element of the model is based on dislocation theory, which describes the movement of dislocations and their interaction with obstacles in the microstructure, such as the strengthening precipitates. The two main strengthening contributions to the strength variations across the weld are the increment in critical resolved shear stress (CRSS) due to co-clusters, $\Delta \tau_{c l}$, and the CRSS 
increment due to $\mathrm{S}$ phase precipitates, $\Delta \tau_{\mathrm{S}}$. Detailed analysis of strengthening and composition of the co-clusters has revealed that $\Delta \tau_{c l}$, can be approximated well as [8,26]:

$$
\Delta \tau_{c l}=\frac{\Delta \mu}{4 \pi \sqrt{2}} f_{c l}^{1 / 2}
$$

where $\Delta \mu$ is the difference between the shear modulus of the matrix and the co-clusters, $f_{c l}$ is the volume fraction of the co-clusters. S rods are considered to be non-shearable and bypassed by an Orowan looping mechanism in both underaged and overaged conditions, and the contribution to the CRSS is taken as [25]:

$$
\Delta \tau_{S}=\frac{0.81 \mu_{m} b}{2 \pi(1-v)^{1 / 2}} \ln \left(d / b\left(0.615 d \sqrt{\frac{2 \pi}{3 f_{S}}}-d\right)^{-1}\right.
$$

where $\mu_{m}$ is the shear modulus of the matrix, $b$ is the Burgers vector, $v$ is the Poisson's ratio for $\mathrm{Al}, d$ is the average diameter of the cross-section of the rod-shaped $\mathrm{S}$ phase precipitates and $f_{S}$ is the volume fraction of $\mathrm{S}$ phase. The equations providing the ultimate superposition of these and other relevant strengthening components:

$$
\Delta \tau_{t o t}=\tau_{s s}+\left(\Delta \tau_{\Sigma}^{q}+\Delta \tau_{c l}^{q}\right)^{1 / q}
$$

where $\Delta \tau_{\mathrm{sS}}$ is the contribution of solid solution strengthening to the CRSS of the grains, $\Delta \tau_{\Sigma}$ is the contribution of the non-shearable S precipitates and dislocations to the CRSS of the grains; the superposition exponent $q$ is an adjustable parameter between 1.0 and 2.0. The local alloy strength is given by:

$$
\sigma_{y}=\sigma_{i}+M \tau_{s s}
$$

where $M$ is a factor related to the number of slip planes that are being activated ( $M$ is sometimes referred to as the Taylor factor), and intrinsic strength of the matrix $\sigma_{i}$ is assumed to be constant throughout the model. $\sigma_{i}$ consists of the yield strength for (commercially) pure aluminium and the contribution of the grain boundary strengthening.

The integrated model is further described in Ref. [25], and derivations and justifications of elements of this detailed model are given in a range of previous publications: 
- the treatment of S phase formation and coarsening is based on classical nucleation and growth models in conjunction with the Lifshitz-Slyozov-Wagner treatment and is given in Refs. [25,43,44];

- the treatment of co-cluster formation is also based on classical nucleation and growth models and is described in Refs. [25,8,45], and experimentally verified for a number of precipitation reactions in heat treatable Al based alloys [46,47,48];

- the strengthening due to $\mathrm{Cu}-\mathrm{Mg}$ co-clusters is considered to be due to modulus hardening and is described in Refs. [8,26];

- the strengthening due to $\mathrm{S}$ phase is considered to be due dispersion strengthening, and is described in Refs. [25,26];

- the minor strengthening mechanisms such as solute strengthening, grain boundary strengthening and dislocation strengthening are discussed in Refs. [25,26,43,49];

- the superposition of different strengthening mechanisms is described in Ref. [43,49].

In applying the model to $\mathrm{Al}-\mathrm{Cu}-\mathrm{Mg}$ alloys nearly all parameters can be obtained from literature data, and ultimately four parameters needed to be fitted to yield strength data. These four fitted parameters are: the pre-exponential factor for precipitation rate of $\mathrm{S}$ phase, the pre-exponential factor for coarsening rate of S phase, the modulus of the co-clusters and $q$. (If also the rate of low temperature hardening due to co-clusters needs to be predicted, also the pre-exponential factor for precipitation rate of co-clusters needs to be determined. This will however not be used in the present work). These parameters were fitted using yield strength vs. ageing treatment data for ageing at 120 to $220^{\circ} \mathrm{C}$. The resulting accuracy for prediction of unseen yield strength data after heat treatment at 120 to $220^{\circ} \mathrm{C}$ is $10 \mathrm{MPa}$ (about 3\%) [25], and results of fits to strength data obtained after ageing at 25 to $220^{\circ} \mathrm{C}$ is presented in Fig. 12. Thus the model is highly accurate for temperatures up to $220^{\circ} \mathrm{C}$, but for welds we will be extrapolating the model well beyond the temperature range for which it was originally verified.

In applying the model, we will be assuming that the influence of the $\Omega$ phase and the GPB2/S" phase and is sufficiently small to be ignored. $\Omega$ phase was identified at positions 3 and 4 , but the estimated maximum volume fraction of $0.5 \mathrm{vol} \% \Omega$ phase at position 3 is less than one tenth of the maximum amount of S phase that can be present (about 6 vol. \%, see Section 4.3 and Fig. 15 ), and hence $\Omega$ phase formation is relatively unimportant. The SAD pattern taken at position 5 (Fig. 9) shows that there is much more $\mathrm{S}$ phase as compared to $\Omega$ phase. Hence throughout the weld and HAZ the influence of $\Omega$ phase formation on the strength and hardness should be very limited, and neglecting it in the present model is thought to be justified. GPB2/S" is not included because it is considered to not provide a substantial contribution to hardening over and above that 
of co-clusters. Diffuse diffraction effects potentially attributable to GPB2/S" were only observed at position 3, but the DSC data from that location indicates that the main low temperature dissolution effect due to co-cluster dissolution is strong, and similar in shape to that observed at other locations. Thus at position 3, strengthening due to co-clusters should be substantial, and any GPB2/S" formation replacing some $\mathrm{Cu}-\mathrm{Mg}$ co-clusters should be relatively inconsequential in terms of hardness/strength.

Detailed finite element (FE) modelling of the heat flow at and around the weld [50] is beyond the scope of the present work, and we will below apply solutions of $T(t, x, y, z)$ for idealised geometries (point heat source, constant heat conductivity and capacity) [51]. To illustrate the principles of the modelling we will consider a simplified case in which the heat treatment experienced by the part of the material that remains solid is equivalent to an isothermal exposure at an (equivalent, effective) temperature $T_{e q}$ for a time $t_{e q}$, followed by extended natural ageing (we will consider ageing for a week, by which time the hardness has stabilised to its plateau value). Simulation by this two-stage treatment is realistic because it takes account of the main hardening and softening reaction in solid alloys, the nucleation, growth (at the expense of coclusters), coarsening and redissolution of S phase and the (re-) formation of co-clusters at low temperatures, i.e. during the final stages of the cooling of the weld and subsequent (re-)ageing (storage) at room temperature. Strong age hardening after re-solidification has also been observed for laser treated 2024 [52].

It has been shown [1] that a realistic treatment of $\mathrm{Cu}$ and $\mathrm{Mn}$ segregation during solidification of the fusion zone in a 2024 weld can be achieved by assuming diffusion in the solid state is negligible, and that the mixing in the liquid state is complete, i.e. following the Scheil [53] approach. Hence, we will here follow that treatment, and consider a simplified, pseudo-binary solidification approach. If in the weld pool the material is fully molten, then on solidification the amount of $\mathrm{Cu}$ and $\mathrm{Mg}$ that is dissolved in the $\mathrm{Al}$ rich phase is determined by the solidus. In the pseudo-binary approach we can apply the simplified phase diagram depicted schematically in Fig. 13. Approximating the solidus by a straight line, the $\mathrm{Cu}$ concentration in the solidifying Alrich phase is given by:

$$
x_{C u}(T)=x_{C u, g} \frac{T_{m}-T}{T_{m}-T_{S o l}\left(x_{C u, g}\right)}
$$

Where $x_{C u, g}$ is the $\mathrm{Cu}$ content of the alloy, $T_{m}$ is the melting temperature of pure $\mathrm{Al}, T_{s o l}\left(x_{C u, g}\right)$ is the equilibrium solidus temperature of the alloy in the pseudo binary approximation. If no 
substantial backdiffusion of $\mathrm{Cu}$ occurs in the solidified Al-rich phase the average $\mathrm{Cu}$ concentration in the Al-rich phase on completion of solidification can be approximated by substituting the average temperature of the solidification range experienced by the sample, i.e. $T=\left(T_{l i q}+T_{\text {sol }}\right) / 2$. This provides:

$$
x_{C u, s o l}=x_{C u, g} \frac{T_{M}-\left(T_{L i q}\left(x_{C u, g}\right)+T_{S o l}\left(x_{C u, g}\right)\right) / 2}{T_{M}-T_{s o l}\left(x_{C u, g}\right)}
$$

where $T_{l i q}\left(x_{C u, g}\right)$ is the liquidus temperature of the alloy. For the zones in which partial melting of the alloy occurs we will assume that $x_{C u}$ increases linearly with temperature between the value for the material that remains fully solid and the materials that solidifies after full melting. Thus, if partial melting occurs $\left(T_{\max }<T_{\text {liq }}\right)$, we can approximate:

$$
x_{C u, s o l}=x_{C u, g} \frac{T_{M}-\left(T_{\max }+T_{S o l}\left(x_{C u, g}\right)\right) / 2}{T_{M}-T_{s o l}\left(x_{C u, g}\right)}
$$

where $T_{\max }$ is the maximum temperature achieved during partial melting. As we are assuming a pseudo-binary approximation, the average $\mathrm{Mg}$ concentration in the Al-rich phase on completion of solidification can be approximated as:

$$
x_{M g, s o l}=x_{M g, g} \frac{x_{C u, s o l}}{x_{C u, g}}
$$

Where $x_{M g, g}$ is the $\mathrm{Mg}$ content of the alloy.

In this pseudo-binary approximation, the solidification path is simplified to consider one solid and one liquid phase. As will be shown below (Section 4.3), this is sufficient to predict strength and hardness in the weld. Evidently, the real solidification path will be more complicated, and will involve the known eutectic phases in the 2024 alloy, e.g. $\theta\left(\mathrm{Al}_{2} \mathrm{Cu}\right), \mathrm{S}\left(\mathrm{Al}_{2} \mathrm{CuMg}\right)$, $\mathrm{Al}_{7} \mathrm{Cu}_{2}(\mathrm{Fe}, \mathrm{Mn})$ and $\mathrm{Al}-\mathrm{Si}-\mathrm{Mn}-\mathrm{Fe}$ phases, and the $\mathrm{L}->\alpha+\theta+\mathrm{S}$ will be the dominant reaction in terms of formation of intermetallic phases. These eutectic reactions and resulting intermetallic phases are expected to be important for several of the properties of the weld, especially the damage tolerance properties. But, as will be shown below (Section 4.3), simplification in present pseudo-binary model does not significantly impair accuracy of strength prediction. 
To illustrate the heat treatment-microstructure-strength model, the modelling results with a constant $t_{e q}$ of $10 \mathrm{~s}$ are plotted in Fig 14a. This figure contains predicted yield strength both after the two-stage ageing at $T_{e q}$ and room temperature, and, to further illuminate the processes, further data is provided on the strength that would be obtained in the hypothetical case where we would cool rapidly after exposure, suppressing the formation of any further (pre-) precipitates after the high temperature exposure at $T_{e q}$. To be able to compare the data in Fig 14a with the measured hardness data (Fig. 1) it should be noted that for Al-Cu-Mg alloys the hardness for aged conditions is not proportional to proof strength [54]. Proportionality is only observed when strengthening is either dominated by clusters (i.e. in substantially underaged conditions) or dominated by $\mathrm{S}$ phase (i.e. in peak aged and overaged conditions). Hence we will convert yield strength data into hardness using a weighted average of two proportionality constants, $\lambda_{1}$ and $\lambda_{2}$, weighted by the contributions of co-clusters and $\mathrm{S}$ phase to the critical resolved shear stress of the grains:

$$
\sigma_{y}=\frac{\lambda_{1} \Delta \tau_{c l}+\lambda_{2} \Delta \tau_{S}}{\Delta \tau_{c l}+\Delta \tau_{S}} H V
$$

where $\Delta \tau_{c l}$ is the predicted contribution of co-clusters to the critical resolved shear stress of the grains and $\Delta \tau_{S}$ is the predicted contribution of $\mathrm{S}$ phase to the critical resolved shear stress of the grains. $\lambda_{1}$ and $\lambda_{2}$ were chosen such that they represent the data in Ref. [54], yielding $\lambda_{1}=2.2$ and $\lambda_{2}=3.2$. The resulting model predictions for hardness vs. $T_{e q}$ are presented in Fig $14 \mathrm{~b}$ and in the same figure also the predicted radius of the $\mathrm{S}$ phase precipitates is presented. From this figure we observe that the modelling broadly explains the hardness levels measured through the weld pool and HAZ, including two hardness maximums. The magnitude of the increase in hardness in going from position 6 to the main peak (position 5) corresponds well with predictions. The model further indicates that drop in hardness in moving from position 5 to 4 is mostly related to coarsening of S phase, and the hardness levels close to the weld nugget are in line with predicted values for substantially resolutionised material, with extensive (re-)precipitation of co-clusters. The resolutionising and reageing by co-cluster formation that occurs when $T_{e q}$ approaches $500^{\circ} \mathrm{C}$ can explain the magnitude of the second hardness peak well. (This is a further indication that the limited amount of coarse $\Omega$ that forms at this position does not significantly influence strength or hardness.) The low hardness at positions 1 and 2 is caused by the reduced amounts of $\mathrm{Cu}$ and $\mathrm{Mg}$ that are available for precipitation hardening in material that was completely molten, with substantial $\mathrm{Cu}$ and $\mathrm{Mg}$ being taken up by the coarse eutectic phases that were observed. 


\subsection{Heat flow - heat treatment models}

The model described in section 4.1 links maximum temperature achieved in weld pool and HAZ to strength and hardness. In order to describe hardness and strength for each position in the welded material we need to model the heat flow in the welded material(s) and predict $T(t, x, y, z)$. Heat flow will depend on a range of factors, such as

- materials properties such as (local) thermal conductivity, $K$, and (local) heat capacity, $C_{p}$, both of which are dependent on temperature, composition and prior heat treatment [55],

- latent heat of fusion

- heat loss due to radiation and convection at the metal - air interface and conduction of heat to clamps used to hold the welded plates, all of which will be temperature dependent, and

- dimensions and shape of the welded material.

The detailed FE model needed to take account of all these factors is beyond the scope of the present paper and would introduce a very wide range of variables that would tend to obscure the main materials related effects. Instead, we will here apply solutions for simplified geometries, which have the benefit of providing a better insight into the materials physics of the process.

Analytical solutions to the heat flow and resulting $T(t, x, y, z)$ for a moving point heat source in (or on) a range of regular shapes and (semi-) infinite media are available [51]. Solutions for $T(t, x, y, z)$ for a heat source moving in one direction over an infinite length can be expressed as a pseudo stationary temperature distribution, i.e. in a co-ordinate system $\left(x^{\prime}, y^{\prime}, z^{\prime}\right)$ that moves with the heat source, $T$ is independent of $t$. A solution that has been considered to be reasonably accurate for fully penetrating weld is the 2D solution, also known as the Rosenthal thin plate solution:

$$
\mathrm{T}-\mathrm{T}_{\mathrm{o}}=\frac{\mathrm{q}}{2 \pi \mathrm{Kd}} \cdot \exp \left(\frac{\mathrm{V}}{2 \kappa} \mathrm{x}\right) \cdot \mathrm{K}_{\mathrm{o}}\left(\frac{\mathrm{V}}{2 \kappa} \sqrt{\mathrm{x}^{2}+\mathrm{y}^{2}}\right)
$$

where $q$ is the heat input per unit time, $T_{o}$ is the initial temperature of the plate, $V$ is the speed of movement of the heat source, $K$ is the thermal conductivity, $\kappa=K /\left(\rho C_{p}\right)$ is the thermal diffusivity, where $\rho$ is the density and $K_{0}$ is the modified Bessel function of the second kind of order zero, which can be evaluated using a series expansion [51]. In this solution of the heat flow equations, no heat is lost by convection or radiation from the boundaries and thus heat flow perpendicular to the plate is zero. It is important to note that $K$ is not constant and depends strongly on the mobility of the main carriers of heat, which are the electrons. $K$ is strongly 
reduced by dissolved alloying elements and the presence of small solute clusters. For our calculations we will consider that for the HAZ the average $K\left(T=20^{\circ} \mathrm{C}\right)$ is the average of $K$ $\left(T=20^{\circ} \mathrm{C}\right)$ for $\mathrm{T} 3$ and $\mathrm{T} 8$ material. Considering further the temperature dependency of the thermal properties the average effective thermal properties to be used in the modelling are those presented in Table 2. The heat input $q$ was chosen such that the position of the peak in hardness immediately adjacent to the weld coincides with the position where the model predicts this maximum to occur, i.e. at $T_{\max }=T_{\text {sol }}$. Examples of the resulting thermal profiles are presented in Fig 15.

To use the temperature predictions in the microstructure model we will apply the principle of equivalent time, which considers that for a reaction that is dominated by a single thermally activated process, the progress of the reaction is a function of $\exp \left(-E_{A} / R T\right)$, where $E_{A}$ is the activation energy for the reaction, and $R$ is the gas constant. From that follows:

$$
t_{e q}(y)=\frac{\int \exp \left(-\frac{E_{a}}{R T}\right) d t}{\exp \left(-\frac{E_{a}}{R T_{e q}}\right)}
$$

We will choose $T_{e q}$ to be the peak temperature and thus we can obtain a $t_{e q}$ and $T_{e q}$ for each point in the material.

Table 2 Thermal properties of 2024 Al based alloy.

\begin{tabular}{|l|l|l|}
\hline & at $20^{\circ} \mathrm{C}$ & $\begin{array}{l}\text { Averaged in HAZ } \\
\text { during welding }\end{array}$ \\
\hline$\rho\left(\mathrm{kg} / \mathrm{m}^{3}\right)$ & $2.77 \times 10^{3}[55]$ & $2.77 \times 10^{3}$ \\
\hline$C_{p}(\mathrm{~J} / \mathrm{kg} . \mathrm{K})$ & $875[55]$ & 1075 \\
\hline $\mathrm{K}(\mathrm{W} / \mathrm{m} . \mathrm{K})$ & $120(\mathrm{~T} 3$ temper $)[55]$ & 181 \\
& $\begin{array}{l}151(\mathrm{~T} 8 \text { temper })[55] \\
190(\mathrm{O} \text { temper })[55]\end{array}$ & \\
\hline$\kappa\left(\mathrm{m}^{2} / \mathrm{s}\right)$ & $0.6078 \times 10^{-4}$ & $0.6078 \times 10^{-4}$ \\
\hline & & \\
\hline
\end{tabular}




\subsection{Heat flow-heat treatment-microstructure-strength predictions and analysis}

Using the data obtained on $T_{\max }(y)$ and $t_{e q}\left(T_{\max }\right)$, we can now combine the heat flow model with the heat treatment-microstructure-strength model, and predict the strength, hardness and microstructure as a function of the distance to the weld centre line. A prediction of hardness vs. $r$ is provided in Fig. 16a. From this figure we can observe that the distances over which the measured hardening and softening occurs correspond well with observations. The model predictions on the microstructure (Fig. 16b) are also broadly consistent with the microstructural data that was gathered.

DSC observations indicated S formation has started at position 5 and is completed at position 4 are consistent with model predictions. In fact, the model predicts $\mathrm{S}$ phase formation is completed at $2 \mathrm{~mm}$ from position 5. Also the amounts of co-cluster dissolution detected by DSC (the endothermic effect up to about 170 to $200{ }^{\circ} \mathrm{C}$ ) are broadly in line with the predictions; e.g. in all samples co-clusters are present, with largest amounts observed for position 3 where the resolutionising and reageing is most extensive. The model further predicts that at a position corresponding to peak hardness (position 5) the diameter of the $\mathrm{S}$ phase is $4.5 \mathrm{~nm}$, whilst the amount of $\mathrm{S}$ phase formed is about $40 \%$ of the maximum amount that can form at that temperature. This predicted size corresponds very well with the TEM observations (Fig. 9), but the amount formed is somewhat higher than the limited reduction in $\mathrm{S}$ phase formation effect observed by DSC would indicate (compare curves 5 and 6 in Fig. 11). It is thought that this is due to the combination of a small inaccuracy (about $0.5 \mathrm{~mm}$ ) in the position from which the DSC sample at position 5 was extracted and a strong variation of $\mathrm{S}$ phase content as a function of distance from weld at position 5 (Fig. 16b). The latter was checked by repeating the experiment on another $2024 \mathrm{~T} 351$ weld, in this case a 13mm gauge full penetration friction stir weld [56]. Thus, two samples were extracted from the friction stir weld at locations corresponding to peak hardness [56]. (In this weld the peak hardness was at about $160 \mathrm{HV}$ and the hardness of the base material well away from the weld was about $140 \mathrm{HV}$. Both values are reasonably close to that of the 2024 VPPA weld.) DSC experiments showed a reduction in heat content of the S phase formation effect of about $70 \%$, which is in line with current model predictions. It is further noted that the assumed small deviation in position of sample would also explain why the reduction in co-cluster dissolution effect at position 5 as compared to position 6 (Fig. 11), is somewhat less than the model would predict (Fig. 16). 
The model predictions indicate that the minimum in hardness at position 4 corresponds to a $T_{e q}$ that has risen to about $430^{\circ} \mathrm{C}$. At that $T_{e q}$, the predicted radius of $\mathrm{S}$ phase precipitates is $15 \mathrm{~nm}$, which corresponds with the TEM data (Fig. 8) which shows $\mathrm{S}$ phase precipitates with radii between 10 and $30 \mathrm{~nm}$.

For further verification we determined the hardness curves for autogeneous (weld without filler) VPPA welds [57]. Fig. 17 represents the hardness curve, together with the data on the weld with 2319 filler. The power densities applied on welding in both methods are nearly the same, but it is clear that the weld with filler gives a somewhat higher hardness in position 3 and 4 . Further, the main hardness peak for the autogeneous weld produces the same hardness level as in the weld with filler, which further supports the model for strengthening outlined above.

\section{Discussion}

The above shows a good correspondence between the measured microstructural parameters (volume fractions of co-clusters and S phase, diameter of S phase) on the one hand and the model predictions of the microstructure. Also the measured hardness variations are consistent with the model. Having constructed the model and verified it by microstructural observations, it has become possible to make a range of predictions on the influence of welding, and pre- and post heat treatment parameters on microstructure and final strength. As would be expected, the model predicts an increase in size of the weld pool and heat affected zones with increasing heat input, $q$. For post welding ageing treatment the model would predict that all the positions in the heat affected zone that have substantial co-cluster precipitation will predicted to respond to an age hardening treatment by virtue of S phase formation.

The present modelling has revealed that strengthening and softening can be satisfactorily explained through reactions involving the $\mathrm{Al}$ rich phase, $\mathrm{S}$ phase and co-clusters, with a pseudobinary treatment of partial melting. The good predictions are achieved notwithstanding a range of approximations that have been made. It is evident that there is ample scope for refining the present model by including more details on the thermodynamics of the system and expansion to real ternary and higher order system calculations. Also the treatment of the kinetics of the reactions can be further refined, for instance by including backdiffusion after solidification and treatments of coarsening, dissolution and reformation through applying Kampmann-Wagner type modelling approaches. For predicting the temperature history of weld and HAZ a range of finite 
element models have been developed. In the remainder of this section we will highlight observations that can be made with regards to further refinement of strength modelling of welds.

It is expected that a more detailed model of the yield strength through the heat affected zone of 2xxx alloy welds can be obtained in a straightforward manner by extending the solid state reaction component of the model to include $\Omega$ formation. However, it should be reiterated that TEM data revealed $\Omega$ formation only occurs at positions 4 and 5 , whilst there is always more $\mathrm{S}$ phase than $\Omega$ phase. Thus the inclusion of $\Omega$ formation will not substantially alter the model predictions, and, more importantly in terms of engineering applications, $\Omega$ formation has no impact on the minimum strength of the weld, which is encountered in the fusion and partial melting zones. Coupling of the microstructure and strengthening model to a finite element based 3 dimensional model is a next objective of our research work. This has recently been demonstrated for friction stir welds of 2024 alloys, and will also be possible for fusion welds, provided the heat flow in the weld pool and semi solid region is accurately predicted (heat flow prediction in solid is relatively straightforward). To obtain the best possible accuracy, a detailed model would also need to incorporate recovery and recrystallisation, which influence strength both directly and indirectly, through changing nucleation, growth and coarsening rates of the strengthening phases. Precipitation during cooling can influence the amount of co-clusters that can form at lower temperatures.

\section{Conclusions}

TEM with selected area diffraction and EDS and SEM with EDS have been applied to study the microstructure of a VPPA weld of Al-Cu-Mg 2024-T351 with Al-Cu 2319 filler. Several zones were identified. In the fusion zone, the microstructure is dominated by dendrites which include eutectic phases of $\theta\left(\mathrm{Al}_{2} \mathrm{Cu}\right)+\mathrm{S}\left(\mathrm{Al}_{2} \mathrm{CuMg}\right)$, the quasicrystalline $\mathrm{Al}-\mathrm{Cu}-\mathrm{Fe}-\mathrm{Mn}-\mathrm{Si}$ formed with ten-fold symmetry formed from $\mathrm{Al}_{7} \mathrm{Cu}_{2}(\mathrm{Fe}, \mathrm{Mn})$ and $\mathrm{Al}_{12}(\mathrm{Fe}, \mathrm{Mn})_{3} \mathrm{Si}$. In the partial melting zone, the microstructure contains a high density of eutectic $\theta+\mathrm{S}$ compound particles. The $\Omega$ phase has been observed between the re-solutionising zone and peak ageing zone, but total amounts present are much lower than amounts of S phase. The hardness peak closest to the fusion zone is attributed to cluster/zone formation after resolution. The hardness peak further away from the fusion zone corresponds to the peak ageing due to $\mathrm{S}$ phase formation. The microstructure development, and resulting hardness and yield strength is modelled using a model which combines primary precipitation, resolution, melting and resolidification (Scheil type) and re- 
precipitation. Precipitation hardening is considered to be dominated by co-clusters and S phase. Semi-quantitative analysis of amounts of S phase and co-clusters from DSC data, S phase sizes obtained from TEM are in good agreement with the model predictions. Hardness profiles through the weld are predicted well. The model can be used for prediction of changes local microstructure, hardness and strength in response to changes in welding parameters.

\section{Acknowledgements}

The authors wish to thank Airbus UK for materials supply and financial support, and the EPSRC and QinetiQ for financial support.

\section{Appendix: The solid state thermodynamic and reaction kinetics model}

The regular solution model is applied to approximate the solvi of clusters and $\mathrm{S}$ phase, the enthalpies of formation, as well as other relevant model parameters, are presented in Table 3. Based on three-dimensional atom probe analysis (3DAP) results [8], the $\mathrm{Cu}: \mathrm{Mg}$ atomic ratio in the clusters is taken as 1:1, and the presence of substantial amounts of $\mathrm{Al}$ atoms in the clusters, approximately in the range of $70-90 \%$, is considered. The formation of the largely insoluble $\mathrm{Al}_{7} \mathrm{Cu}_{2} \mathrm{Fe}$ and $\mathrm{Al}_{20} \mathrm{Cu}_{2} \mathrm{Mn}_{3}$ particles and undissolved $\mathrm{Al}_{2} \mathrm{CuMg}$ is accounted for in a treatment similar to that used in [43].

The transformed fraction of precipitates during ageing can be described by the Starink-Zahra (SZ) model for nucleation and growth [45-48]:

$$
\alpha(T, t)=1-\left([k(T) t]^{n} / \eta_{i}+1\right)^{-\eta_{i}}
$$

where $\alpha$ is the transformed fraction, $\mathrm{n}$ is the reaction exponent, $\eta_{\mathrm{i}}$ is the impingement exponent and $k(T)$ is the rate constant which can be expressed by an Arrhenius relation with the activation energy $E_{\text {eff. }}$ The amount of clusters is modelled by assuming $\mathrm{S}$ phase forms at the expense of the clusters:

$$
x_{c l}=x_{c l}^{\max } \alpha_{c l}\left(1-\alpha_{S}\right)
$$


where $\mathrm{x}_{\mathrm{cl}}$ is the amount of clusters formed and $x_{c l}^{\max }$ is the maximum amount of clusters that can form if no other precipitates were present. The evolution of the average size of the precipitate, $\bar{l}(t)$, is approximated by $[43,58]$ :

$$
\bar{l}(t)=\bar{l}_{g}(t)+\bar{l}_{c}(t)-\bar{l}_{0}=\bar{l}_{0} \alpha^{1 / 3}+\bar{l}_{c}(t)-\bar{l}_{0}
$$

where $\bar{l}_{g}(t)$ is the average size of the precipitates in the nucleation and growth stages, $\bar{l}_{c}(t)$ is the average size during the coarsening stage [43], which is taken to be in line with the classical coarsening theory, and $\bar{l}_{0}$ is the average size at the start of coarsening. 
Table 3 Parameters used in the model predictions

\begin{tabular}{|c|c|c|c|}
\hline Symbol & Definition & Value & Comments \\
\hline$b$ & Magnitude of the Burgers vector & $0.286 \mathrm{~nm}$ & \\
\hline$\mu_{A l}$ & Shear modulus of the Al matrix & $26.2 \mathrm{GPa}$ & \\
\hline$v$ & Poisson's ratio & 0.33 & \\
\hline$\Delta H^{c l}$ & $\begin{array}{l}\text { Formation enthalpy of the } \mathrm{Cu}- \\
\mathrm{Mg} \text { co-clusters }\end{array}$ & $38 \mathrm{~kJ} / \mathrm{mol}$ & \\
\hline$\Delta H^{S}$ & Formation enthalpy of S phase & $77 \mathrm{~kJ} / \mathrm{mol}$ & \\
\hline$\sigma_{i}$ & Intrinsic strength & $30 \mathrm{MPa} *$ & For commercial purity alloys \\
\hline$k_{C u}$ & $\begin{array}{l}\text { Strengthening coefficient for } \mathrm{Cu} \\
\text { solid solution strengthening }\end{array}$ & $50 \mathrm{MPa} / \mathrm{at} \% \mathrm{Cu}$ & \\
\hline$k_{M g}$ & $\begin{array}{l}\text { Strengthening coefficient for } \\
\text { Mg solid solution strengthening }\end{array}$ & $13.6 \mathrm{MPa} / \mathrm{at} \% \mathrm{Mg}$ & \\
\hline$M$ & Taylor factor & 2.6 & $\begin{array}{l}\text { From self-consistent modelling of } \\
\text { deformation of texture free } \\
\text { polycrystalline Al [59] }\end{array}$ \\
\hline$q$ & Superposition exponent & 1.3 & Fitting parameter \\
\hline $\bar{l}_{0}$ & $\begin{array}{l}\text { Average radius of } S \text { rods at the } \\
\text { start of coarsening }\end{array}$ & $4.7 \mathrm{~nm}$ & Fitting parameter \\
\hline$\eta_{i}^{S}$ & $\begin{array}{l}\text { Impingement exponent for } \mathrm{S} \\
\text { precipitation }\end{array}$ & 1 & Chosen based on the literature [35] \\
\hline
\end{tabular}




\section{References}

[1] Norman AF, Drazher V, Prangnell PB. Mater Sci Eng A 1999;259:53.

[2] Schillinger DE, Betz IG, Hussey FW, Markus H. Welding J 1983;42:269S.

[3] Lefebvre F, Wang SC, Sinclair I, Starink MJ. Mater Sci Forum 2002;396-402:1555.

[4] Lefebvre F, Ganguly S, Sinclair I, Mater Sci Eng A 2005; 397: 338.

[5] Lefebvre F, Sinclair I, Mater Sci Eng A 2005; 407: 265

[6] Owen RA, Preston RV, Withers PJ, Shercliff HR, Webster PJ. Mater Sci Eng A 2003;346:159.

[7] Starink MJ, Gao N, Kamp N, Wang SC, Pitcher PD, Sinclair I. Mater. Sci. Eng. A 2006; 418: 241.

[8] Starink MJ, Gao N, Davin L, Yan J, Cerezo A. Phil Mag 2005; 85: 1395

[9] Starink MJ, Cerezo A., Yan J, Gao N: Phil Mag Lett, 2006, in press

[10] Bagaryatsky YA. Dokl Akad S.S.S.R 1952;87:397 \& 559.

[11] Silcock JM. J Inst Metals 1960-61;89:203.

[12] Cuisiat F, Duval P, Graf R. Scripta Met 1984;18:1051.

[13] Shih H, Ho N, Huang JC. Metall Mater Trans A 1996;27:2479.

[14] Wolverton C. Acta Mater 2001;49:3129.

[15] Charai A, Walther T, Alfonso C, Zahra AM, Zahra CY. Acta Mater 2000;48:2751.

[16] Wilson RN, Partridge PG. Acta Mater 1965;13:1321.

[17] Ringer SP, Hono K, Polmear IJ, Sakurai T. Acta Mater 1996;44:1883.

[18] Ringer SP, Caraher SK, Polmear IJ. Scripta Mater 1998;39:1559.

[19] Wang SC, Starink MJ. Inst Phys Conf Ser 2004;179:277.

[20] Wang SC, Starink MJ. Mater Sci Eng A 2004, 386: 156.

[21] Kovarik L, Gouma PI, Kisielowski C, Court SA. Mills MJ, Acta Mater 2004;52:2509.

[22] Reich L, Ringer SP, Hono K. Phil Mag Lett 1999;79:639.

[23] Wang SC, Starink MJ. Int Mater Rev. 2005; 50: 193

[24] Perlitz H, Westgren A. Arkiv. Kemi. Mineral Geol 1943;16B:No13.

[25] Starink MJ, Yan J. Proc ASM Materials Solutions Conf. 2003, 1st International Symposium on Metallurgical Modeling for Aluminum Alloys (M. Tiryakioglu and L.A. Lalli, Eds.), October 12-15, 2003, Pittsburgh, PA, USA, ASM International, Materials Park, Ohio, USA, pp. 119-126.

[26] Starink MJ, Yan J, Gao N. Mater Sci Eng A 2004; 387-389: 222.

[27] Ringer SP, Sakurai T, Polmear IJ. Acta Mater 1997;45:3731.

[28] Wang SC, Starink MJ, Gao N. Scr Mater 2006; 54: 287.

[29] Auld JH. Acta Crystallogr 1972; 28A: S98 suppl.

[30] Auld JH. Mater Sci Techn 1986;2:784.

[31] Kerry S, Scott VD. Metal Science 1984;18:289.

[32] Knowles KM, Stobbs WM. Acta Cryst 1988;44B:207.

[33] Garg A, Howe JM. Acta Metall Mater, 1991;39:1939.

[34] Vaughan D, Silcock JM. Phys Stat Sol 1967;20:725.

[35] Starink MJ. Int Mater Rev 2004; 49: 191.

[36] Wang SC, Li C, Yan MG. Acta Met. Sinica 1990;A3:104.

[37] Wang LM. Flower HM, Lindley TC, Scripta Mater 1999;41:391.

[38] Gao N, Davin L, Wang S, Cerezo A, Starink MJ. Mater Sci Forum 2002;396-402:923.

[39] Davin L. PhD thesis, University of Oxford, UK, 2004

[40] Radmilovic V, Killas R, Dahmen U, Shiflet GJ. Acta Mater 1999; 47: 3987

[41] Myhr OR, Grong Ø, Fjær HG, Marioara CD. Acta Mater 2004; 52: 4997.

[42] Nicolas M, Deschamps A. Acta Mater 2003; 5: 6077.

[43] Starink MJ, Wang SC. Acta Mater 2003;51:5131.

[44] Starink MJ, Wang P, Sinclair I, Gregson PJ. Acta Mater 1999;47:3841. 
[45] Starink MJ, Zahra AM. Phil Mag A 1998:77:187.

[46] Starink MJ, Zahra AM. Thermochim Acta 1997;292:159.

[47] Starink MJ, Zahra AM. Acta Mater 1998;46:3381.

[48] Starink MJ. J Mater Sci 2001;36:4433.

[49] Starink MJ, Wang P, Sinclair I, Gregson PJ. Acta Mater 1999;47:3855.

[50] Zhu XK, Chao YJ. Computers \& Structures 2002;80:967.

[51] Carslaw HS, Jaeger JC. in 'Conduction of Heat in Solids', $2^{\text {nd }}$ edition, Clarendon Press, Oxford, 1959, 266-270.

[52] Noordhuis J, de Hosson JThM. Acta Mater 1993;41:1989.

[53] Scheil E. Z Metallkd. 1942;34:70.

[54] Starink MJ, Sinclair I, Gao N, Kamp N, Gregson PJ, Pitcher P, Levers A, Gardiner S. Mater Sci Forum 2002;396-402:601.

[55] Aluminum and Aluminum Alloys, ASM Specialty Handbook, J.R. Davis (ed.), ASM International, Materials Park, OH, USA, 1993.

[56] Booth DPP. PhD thesis, 2003, University of Southampton.

[57] Lefebvre F. PhD thesis, 2003, University of Southampton.

[58] Starink MJ. Mater Sci For 2006, in press.

[59] Clausen B, Lorentzen T, Leffers T. Acta Mater. 1998; 46, 3087. 